\title{
Trapped in the Duality of Structure: An sTs Approach to Engineering Ethics
}

\author{
Tsjalling Swierstra and Jaap Jelsma
}

\section{Introduction}

There was a remarkable increase in attention given to ethical issues concerning technology in the second half of the previous century. This increase followed the deepening societal impact of technology, and the growing insight into its benefits as well as its potential for disaster. More or less parallel to this development in ethics, sociological studies started to delve empirically into the contextual development of the substance of science and technology. This latter move from the philosophy of technology towards a more empirical type of science and technology studies has lead to a growing interest in everyday practicalities of technology development. However, science and technology studies do not simply open up new theoretical avenues. We shall demonstrate that they also confront moral philosophers with some tough challenges.

Until recently, the moral philosophy of technology could be roughly divided into an Anglo-Saxon and a Continental tradition (Mitcham and Nissenbaum 1998). Within the former tradition, especially in the United States, the ethical approach has been intimately connected with efforts made by the administration to watch over technology by means of technology assessment. The main focus in this policy has been on the just distribution of the costs, benefits and risks of particular technological developments. In sharp contrast, the Continental tradition focussed on the cultural and moral consequences of the general dominance of technology in Western societies, and on the possible rise of a quasi-totalitarian technocracy. The keyword here is alienation, i.e., the situation where the subject is ruled by the object, that is, man is governed by technology of his own making. The conflict between instrumentalist and substantive conceptions of technology formed the issue of the debate between the traditions. In the former conception, technology is a value-neutral instrument that has to be wielded wisely and fairly. In the latter, modern technology embodies substantive values like control and manipula- 
tion. For that reason, existing technology has to be condemned as a whole and, if possible, replaced by an alternative, less dominating type.

In recent years both traditions have come under attack for their frequent a priori and monistic conception of technology and for their rather deterministic view of technology development. Critics maintain that both philosophical traditions neglect the internal workings of technology development, its contingency, the social influences that co-determine it, and its man-made character in general. As a result of this, both traditions lack the conceptual means for developing a strategy of effective control, waking up - as it were with the hellhounds at the door. Therefore, philosophers of technology in general, and ethicists in particular, are advised to listen carefully to their colleagues from the sociology of science and technology (De Vries 1989). Their "science and technology studies" open up wide vistas on the inner workings of technology development. What becomes visible makes the traditional philosophy of technology difficult to maintain.

This sociological opening-up of the "black box" of technology finds its counterpart in the efflorescence of what is now called "engineering ethics". This type of applied ethics not only deals with the results of technology-leaving the content of technology development securely to the minds and hands of engineers - but also with the practice of technology-in-the-making as well. If technology is man-made, then, in principle, man can be expected to make conscious and ethical choices about the course of its development. The mission of engineering ethics is the amelioration of the practical choices engineers make, by introducing moral standards and emphasising ethical skills. Engineering ethics is a form of professional ethics. It directs itself towards engineers because they are the primary actors in the technology venture. It is they who design and develop the hardware (and, increasingly, also the software) and command the necessary technical expertise. As experts, they are in a privileged position to foresee and assess the possible consequences of their technologies. When sufficiently trained in ethics, so the assumption goes, they will utilise their influence to make better technology with less undesirable consequences for society and the environment. Thus, the core business of engineering ethics can be characterised as helping and motivating engineers to take their professional responsibilities to heart. ${ }^{1}$ In the meantime, this trend has reached the policy makers. For instance, in the early 1990s, the Dutch Parliament asked the Minister of Science and Education to ensure that young engineers receive an education in ethics (see Ritzen 1991).

However, in a recent, thought-provoking article, William Lynch and Ronald Kline (2000) took a critical look at an important current within modern engineering ethics. As a discipline, engineering ethics examines and dis- 
cusses issues as diverse as the avoidance of conflicts of interests, the protection of trade secrets and confidentiality, the right to dissent, professional responsibility, and the obligation to protect public safety, health, and welfare. But however broad this range of issues, much of engineering ethics has been directed towards ensuring "that engineers meet their obligation to the public ... regardless of any pressures they may encounter in a corporate environment. Whether emphasising individual moral reasoning or professionally normative standards, engineering ethicists have been particularly concerned to help ensure that the engineering will resist social pressures on the job" (Lynch and Kline 2000, 197). In particular, engineering ethics focusses on cases of socalled "whistle blowing". In such cases, we meet responsible engineers who entertain grave doubts about the safety of a particular new technological project. But they are often overruled by managers who wave aside these doubts because they are propelled by conflicting goals like their own or the company's reputation, the financial consequences of not meeting contractual obligations towards associates, and so on. The dilemma is always whether individual engineers should make their knowledge of immanent disaster public, even though, by doing so, they break their vow of loyalty and confidentiality towards their employer and, more likely than not, suffer great personal cost.

Lynch and Kline wonder how much heroism we can expect from responsible engineers. Taking their cue explicitly from modern science and technology studies, they argue that engineering ethics would do better by paying "attention to the complexities of engineering practice that shape decisions on a daily basis". In this way, engineering ethics will help engineers "to identify features of their everyday practice that could contribute to ethically problematic outcomes before clear-cut ethical dilemmas arise" (197). Safety risks do not spring up overnight but are generally the result of a slow and gradual process that can and should be influenced by responsible - not heroic - engineers. The authors offer willing engineers ways to be responsible without having to be a (semi-suicidal) hero.

Our primary interest here is not so much Lynch and Kline's advice to engineers but rather why engineering ethicists are so keen on whistle blowing. According to Lynch and Kline, it is "the focus on individual or professional autonomy [that] can lead to an excessive focus on the conflict between engineers and management" (197-8). In our view, it is not the focus on autonomy that leads to this pre-occupation with whistle blowing, but rather the focus on the moral responsibility of engineers. Engineering ethics addresses responsible engineers, and it seeks to elaborate this sense of responsibility. Cases of whistle blowing are well suited to support this pursuit. This can be seen as follows.

Moral responsibility is a core theme of moral philosophy. For our purpose, 
however, we do not have to go into all the complexities of the debate. To be responsible for something is broadly understood as to be answerable for it. But one is not always answerable for everything. To be answerable, certain conditions have to be met. According to most moral philosophers, ${ }^{2}$ and to most people in ordinary life as well, individuals can be held responsible, that is answerable or accountable, for their actions (and the consequences), if fourconditions are met:

1 To consider an actor responsible, $\mathrm{s} /$ he should be imputable. Imputability is most commonly understood as being in possession of one's rational capabilities at the moment one performed the imputed action. This condition is well known in everyday experience. When someone wrongs us, we blame him or her and ask for compensation, apologies, or punishment. However, if a child, or someone suffering from a delirium, hurts us, we do not take him or her to be accountable in the normal sense. We do not blame the child or the madman, for "s/he did not know what s/he was doing".

2 The actor should actually have performed the action for which s/he is considered responsible. We stop blaming someone if s/he convinces us that, in fact, $\mathrm{s} /$ he did not execute the action that hurt us. In severe cases, a third partysuch as a court or a jury - is summoned to find out the truth about these facts. Of course, it is equally possible to hold someone responsible for not having acted in a situation where $\mathrm{s} /$ he should have acted.

3 The actor should have acted on his or her own free will, i.e., should not have been under external pressure or hindered by circumstances outside his/her control. If someone breaks a promise to meet us at a certain time, we do not hold this against him/her if it turns out that, on the way, s/he was abducted or had an accident. Sometimes this condition is not recognised as a separate condition but is considered as implied in the first condition. In that case, a responsible person is understood as being rational and free. However, for our purposes, we prefer to differentiate rationality and free will.

4 The actor can only be held responsible for the consequences of his/her actions if these were or could have been foreseen. Few people will blame Diesel for the environmental problems caused by automobiles with diesel engines.

These four conditions spell out the conception of moral responsibility that (rightly) prevails in ethics and common sense in general. ${ }^{3}$

It is now easy to see that cases of whistle blowing fit in quite well with this 
conception of moral responsibility. In such cases, most of the four conditions are met. The brave engineer is - of course - rational, $\mathrm{s} / \mathrm{he}$ can be the clear and definite cause of a particular consequence (by going public, s/he ensures that our safety will not be put in danger), and it is by and large foreseeable what the outcome of this action will be (the danger will be averted, the company criticised). Only one condition is not met. There is considerable (moral) pressure exercised on individual engineers to keep their mouths shut. They are not free. So it is toward this condition proper that most of the attention in engineering ethics is directed.

How instructive and even inspiring whistle blowing may be, arguments that situations like these exhaust the moral dimension of engineering hardly carry conviction. To force the issue: by focussing on whistle blowing, engineering ethics evades the real problem. Within the practice of modern technology, the cases in which the four conditions for individual moral responsibility are met-if ever-are the exceptional ones. The outcome of much sociological research in science and technology radically undermines the prevailing, commonsense conception of individual moral responsibility that also underlies engineering ethics. To make this clear, we shall go through the four conditions of moral responsibility once again.

The first condition is left untouched by science and technology studies. No one argues that engineers are out of their mind. However, science and technology studies do interfere with the remaining three conditions of moral responsibility. The second condition prescribes that the actor actually performed the action for which s/he is held accountable. In the case of engineers, the determination of this causality is not as easy as it may seem. Modern engineers are, more often than not, relatively small cogs in a large and complex machine. Therefore, when some consequences of new technologies turn out to be less desirable than expected, it is generally impossible to relate these consequences to the actions of specific engineers in a straightforward manner. As technology studies have repeatedly shown, modern technology is essentially a collective and complex enterprise. However, individual engineers are not usually only small cogs, they are also relatively powerless ones. They typically work in hierarchical organisations and have little room to follow their own choices. Thus, the third condition - about freedom to act - is not met either. Finally, the fourth condition holds that a person can only be held responsible for the consequences if those were or could have been foreseen. But science and technology studies have shown that it is hard, if not impossible, to predict with any accuracy the future consequences of new technologies for society and the environment (e.g., see Collingridge 1980).

Thus, if we follow the sociologists, the conditions for moral responsibility 
are seldom, if ever, met inside the modern techno-scientific enterprise. Within such an environment, it is not only hard but also often impossible to ascribe moral responsibility to individual actors. Therefore, engineering ethics is in constant danger of committing moralism. By this we mean the attitude of burdening individuals with moral demands and responsibilities they cannot possibly meet. There is also the connected danger of naively expecting engineers to assume their responsibility actively. In its passive (or retrospective) form, responsibility equals liability or accountability. On the other hand, in its active (or prospective) form, responsibility is seen as a desirable character trait, as a virtue. An actively responsible person has an acute sense of his/her duties, performs them well, and shows vision. But how strong is the motivation of an anonymous cog, without real power or foresight, to behave responsibly in this active sense? Not very strong, one would expect.

Our main contention is that engineering ethics should directly reflect the problematic status of individual moral responsibility, instead of skipping this important issue by orienting all its attention to those rare cases where most conditions for realising this moral responsibility are met. If it continues to do so, engineering ethics not only runs the risk of neglecting the major part of normal engineering practice, but also exposes itself to the associated danger of unwittingly molding situations to make them fit the contours of moral individual responsibility. The case of the Challenger disaster is a case in point here. ${ }^{4}$ But Kline and Lynch's solution does not seem very satisfactory either. Even though they correctly chastise mainstream engineering ethics for its too-narrow focus on whistle blowing, they only focus upon the symptom. They overlook the underlying cause of this narrow focus: the desire to find situations in engineering practice that do fit the bill of individual moral responsibility with which ethicists are so comfortable. This means they stay within the bounds of mainstream engineering ethics by assuming that the use of science and technology studies will leave unscathed the core of engineering ethics, the individual conception of moral responsibility.

In the following, we shall take up the challenge of science and technology studies with regard to engineering ethics. However, we shall not argue that an individual notion of moral responsibility is obsolete, and engineering ethics along with it. Ultimately, any normative reflection on the development of modern technology has to address the responsibility of actors, i.e., individuals. Human actors can act responsibly, networks cannot. ${ }^{5}$

Therefore, a normative approach to science and technology cannot say goodbye to moral responsibility. But its content and its scope will have to be re-thought in the light of the findings of modern science and technology studies. We want to contribute to this re-thinking by presenting an empirical 
study showing the changing role of moral responsibility in a normal engineering practice. Our research for this study is based on data that were collected at our university during the 1990 os (see next section).

With this study, we aim to supply evidence that the lack of incentive for moral behaviour in engineering is not a property of modern technology-inthe-making as such. It is, to a large degree, the consequence of the specific way this technology-in-the-making is organised. If this organisation is changed properly, the way moral responsibility is exercised by engineers may also change, and may become more productive. Therefore, an engineering ethics that takes the moral responsibility of engineers to heart should not omit reflection upon organisational reforms that could clear away the current impediments to practising individual moral responsibility in engineering.

\section{Research approach and data}

We carried out our research in a number of steps that are followed through in the structure of the study presented below:

Starting research at the level of individuals

As we argued above, individuals have to play one role or another in the moral steering of technology. Therefore, it is legitimate to start our argument at this individual level. However, to avoid moralism, it is of the utmost importance to keep in touch with the conceptions of moral responsibility brought forward by the moral agents themselves - the engineers. They can be safely assumed to have their own ideas on responsibility - because they have the most interest in doing so. Apart from this matter of principle, there is also a more pragmatic reason to start with what individual engineers have to say. If a theoretical conception of moral responsibility is to have any chance at all of being accepted by its addressees, this conception should be developed in a dialogue with them. This is not a hollow courtesy. In a recent study, Radder has pointed out that bioengineers are highly critical of suggestions offered to them by moral philosophers for the ethical improvement of their technological practices (Radder 1996).

Collecting and analysing empirical data

To portray the moral agents, we sought empirical answers to the question concerning the way in which engineers themselves reflect on their responsibility as techno-scientists. Scanning the literature on ethical aspects of engineering practice delivered no systematic data about typical ways in which practising engineers think about their social responsibility. Fortunately, however, we did have access to a modest but interesting data set collected during 
the course of an experimental impact assessment project - called SESR, i.e., Social Effects of Scientific Research - at our university (University of Twente). This is a university consisting of a number of large technical departments on the one side, and smaller schools of philosophy, social sciences, and business on the other.

The SESR project started in 1989 and continued on through the 1990s. Its objective was to develop measures for stimulating discussion about the social effects of technical research - either planned or already in progress - at our university. The SESR project was initiated in reaction to the conclusion of a highly controversial research contract between a research group in the Technical Physics Department and Urenco, a nearby uranium-enrichment facility. Through this contract, the university became linked to applied research in laser enrichment of uranium in a business context. Particularly the potential military applications of this kind of research triggered excitement about this contract in the university community and in the local press. This excitement can be understood from the fact that, at the beginning of the 1970s, the university had declared - by a decision of the Board - that it would not engage in research with military applications. To neutralise the controversy resulting from the Urenco contract, the Board of the University launched the SESR project (see Jelsma and Van de Poel 1992). In the framework of this project, scientists in the technical departments (mostly engineers) were interviewed about their views on the social responsibility of practitioners. These interviews are the primary source of data for our research.

Typical statements by the interviewees are presented in the first part of the study. This is done by arranging these statements according to the four conditions of moral responsibility as spelled out in the introduction. In the second part, we critically appraise the engineers' opinions against the same conditions, and we question the tenability of these conditions in the context of a modern academic research setting.

Extending the scope of research beyond the individual level

The inclusion of societal criteria in matters concerning the funding of university research programs - one of the measures resulting from the SESR project - opened the opportunity to investigate whether these criteria influenced the way in which questions of societal responsibility were handled and research decisions were made. We studied this aspect at the researchteam level, and report on it in the third part, in a concise case study on the choices made within a research project on biodegradable plastics within our university. We derived the data for this study from an investigation carried out by one of our graduate students (Schaareman 1997). This investigation is based on in-depth interviews with technical scientists involved in the proj- 
ect, especially the project leader and the Ph.D. student who carried out the research.

Connecting the individual and institutional level

In the final section, we connect both levels of moral action in terms of an incentive structure at the university level, setting the stage for the moral agency of individual scientists.

\section{Interviews with engineers about their responsibility as technical scientists}

In presenting the interview results, we shall leave aside the rather trivial first condition for moral responsibility, i.e., rationality, for the simple reason that it is never seen as a problem in the case of engineers. Thus, to be attributed moral responsibility or to accept it, the three remaining conditions are:

A the actor has to have acted, s/he had to be the cause of the consequences;

$\mathrm{B}$ s/he has to have acted freely and willingly; and

$\mathrm{C}$ s/he has to have done so knowingly - both with reference to the relevant facts of the case and with reference to the relevant norms and values. The engineer should at least have been in the position to acquire sufficient knowledge about the consequences of his/her professional actions and their (un)desirability to make responsible actions possible.

To what degree do engineers themselves feel that these three conditions are fulfilled in their own daily practice? For answers to this question, we shall turn to the interviews.

\section{A. Actors and causality}

Although, at first sight, it may seem a fairly straightforward matter, the causality between actors and actions is often difficult to establish in the reality of modern technology development. Not only do we find ourselves confronted with the so-called problem of "many hands", but more often than not, the causal chain between action and consequence is hard to establish. One reason has been mentioned already: the fact that modern technology development is a multi-actor enterprise. But our respondents frequently pointed to another, albeit related, reason. In the case of technology, there is inevitably a gap between the designer and the user of technology. Our respondents repeatedly referred to this gap. In their view, they hardly "do" anything when it comes to 
the implementation of their research results. That's all other people's work: "one cannot prevent improper use of one's results". Engineers only come up with the instruments, others are responsible for the consequences of their use. This is one important reason for the engineers' belief that their individual responsibility for the possibly negative societal consequences of their work is severely restricted.

However, exceptions to this view were reported. Some respondents did feel that, in their line of research, it is quite possible to foresee how the outcomes of their work will be used: "Everyone who does not live in an ivory tower knows what use society will make of his work". And as soon as a designer is aware of what future use will be made of his or her instruments, $\mathrm{s} / \mathrm{he}$ is co-responsible for this use to a certain degree. This view seems to correspond to commonsense notions of responsibility: if I give a gun to a known killer, I am co-responsible if s/he goes out to kill someone with it. Interestingly enough, this is not the reason why some respondents are quite clear about their refusal to work for the military, or why several other respondents said they try to steer away from controversial research. On the contrary, this notion of co-responsibility is most often put forward in those cases where the respondents feel the uses of their technologies are beneficial. Most technological designs are developed with such beneficial goals in mind, and engineers are keen to accept co-responsibility for these.

\section{B. Freedom of design and of research into the consequences of the design}

In the case of technology development, there can be more or less freedom to perform two basic kinds of activity: (1) design work proper and (2) research into the possible consequences if these technological designs become implemented. Thus, in discussing the moral responsibility of engineers, we have to distinguish between these two levels of freedom.

1 According to our respondents, their freedom to design what they want is limited. The reason for this is that they feel forced to seek collaboration with business organisations and therefore to submit themselves, to a certain degree, to commercial incentives and to the necessity to compete with market parties. Although they feel market orientation curtails their academic freedom, they still seek collaboration with parties closer to the market for three main reasons. The first reason is economic: business provides the funds necessary to do research. But they also come up with less down-to-earth reasons. Universities are not the only knowledge institutions in modern society. Firms have vast research facilities, and the knowledge produced there is often only 
accessible to academics through collaboration: "[by collaborating] you get access to confidential information about what these companies are working on". Enhancing the practical relevance of academic research is a third goal that counts in the collaboration with business organisations: "It is a matter of mutual interest that universities, which are objective, and industry, which is close to practical problems, collaborate. If not, you get irrelevant universities and impractical standards". Several respondents made it clear that they regard an enlargement of the probability that their ideas will be put into practice as a substantial advantage of collaborating with business.

However, the perception of these advantages does not mean that our respondents close their eyes to the potential reverse side of this coin. Collaboration with business may be inevitable because of the benefits it offers, but this does not mean that there are no costs. Two kinds of costs were repeatedly mentioned. First, the need to collaborate decreases one's scope for adopting a principled, moral stance in those cases calling for such a stance: "There is an increasing need for funds from outside the university. And then discussions become more difficult. The need for money leaves little room for principles". Another respondent remarked that he would "lose his credit with external financiers, and put an end to the collaboration" if he were to take a critical stance. Second, to our respondents, the main criterion for success still remained scientific relevance: "going purely for the money is despicable". However, they saw this kind of scientific attitude as being different from the primary motivations of their business partners.

2 How free do our respondents feel to invest time and money in finding out about the future social and environmental consequences of their technological innovations? Most respondents made it abundantly clear that neither the university nor their business partners appeared to be much interested in early assessments of the possible adverse consequences of their research activities. Many of the respondents believed that the university's lack of interest in this matter is shown by the fact that it primarily pushes its employees toward scientifically relevant output. As one respondent told us: "We work hard on the technical side, but not on the social one. That should be taken up by the university, but not by our department. We are already forced to swim very hard to keep ourselves from drowning. In that respect, the world is very hard and simple". This is not to say that our respondents made the general impression of suffering severely from this lack of stimulation. One characteristic quote illustrates this as follows: "It will be very difficult to make funds available [for looking into the consequences]. We have different priorities within our department. Education and research are in a tight spot as it is. And we do not 
want regulations and facilities at university level because, in the end, that only swallows up the scarce funds".

We conclude that the freedom of these engineer-designers is restricted on two levels. First, they feel forced by financial and professional reasons to enter into collaboration with business partners, restricting the possible avenues for inquiry. Second, neither these business partners nor their direct employer is perceived as being much interested in impact assessment along moral standards. Both push the engineer-designer in directions deemed commercially and/or scientifically important. But it is not only a matter of pragmatic reasons, i.e., funds and time, that discourages respondents from investing in impact assessment. There are also more substantive arguments why they do not systematically investigate the possible ethical, societal, and environmental consequences of their technological work. This leads us to the third condition.

\section{Knowledge of the consequences}

Basically, the respondents came up with five more fundamental reasons why they cannot collect valid knowledge about the consequences of their work. First, the possible consequences of newly implemented technologies are too manifold, too complex to be foreseen with any acceptable degree of certainty: "Everything we do has social consequences". Second, these consequences often take too much time to manifest themselves: "It is a major problem that, in the long run, these consequences are unpredictable". Third, more often than not, desirable consequences are intrinsically linked to less desirable ones. If you want the one kind, you simply have to accept the other: "Even if there were military uses, I would not stop my research because it will simultaneously yield results that are crucially important for the medical sector". Fourth and this is perhaps the most basic reason - it is, by definition, not the technology developer who determines what the consequences will be, but the user of the technology: "Yes, there are unintended consequences. But these do not have much to do with the technology. You cannot influence them. After twenty-five years, I still cannot fathom how the medical sector works. If we come up with a cheaper technique, the result often is that the total costs go up because this technique is more often employed than before, and the physicians can write out bills each time". We have seen this type of argument before, in a slightly different context. There the argument was that "user autonomy" washes out the causality of those who designed the instruments and the consequences of use. Here the point is different: "user autonomy" means that the consequences of a new technique cannot be adequately known beforehand. 
Finally, the normative evaluation of probable consequences is said to remain inevitably a matter of subjective taste: "What is deemed socially relevant is also a matter of your political stance”.

\section{Critical evaluation of the interview data}

Which notion of moral responsibility issues from these deliberations by the engineers themselves on the three basic conditions: causality, freedom to act, and knowledge about the consequences? Let us take the three conditions one at a time. We shall see that there is much that is convincing and that should be taken into account to avoid moralism, as defined above. But there are also some points that are less convincing, and some inconsistencies that should make us stop in our tracks.

re A Reflecting on their remarks about causality, we see the interviewees hiding behind their academic freedom when denying their responsibility for unforeseen negative consequences: they did not do anything possibly contentious, the users are responsible. But when the technology turns out well, they are the first to claim responsibility. Nevertheless, there is considerable truth in these claims about causality (or lack of). However, this is not the whole story. Whether an engineer can be considered as a moral actor, i.e., whether s/he can be held responsible for the use made of his or her designs, depends to a large extent on the knowledge variable (that is condition B): could s/he have foreseen these uses and therefore (some of) the consequences of the technology s/he designed? In the interviews, respondents offered both pragmatic and fundamental reasons for not being able to assess these uses and consequences: no time and no money, and they even called this type of foresight essentially impossible. In appraisal of this pragmatic argument, we can say that it covers up the choice that is involved here: time and funds could, in principle, have been used differently. With reference to the second, more fundamental argument, it has been observed that, although it may indeed be impossible to foresee all the consequences of a technological design, at least some of these consequences can be anticipated. This is all the more so because a technological artifact has a "script" (Akrich and Latour 1992), i.e., it prescribes to some extent the uses that will be made of it. It should be noted that, even if this specific feature of technological artifacts has now been sufficiently established by the critics of the instrumentalist vision of technology, this vision remains dominant among engineers. 
re $B$ Concentrating on their remarks about their own freedom of action, we find that the engineers themselves point out what sociologists call "the network character" of technology development. According to that conception, individual engineers have a very restricted moral agency. Their practical options are severely limited by the fact that technology development is not a matter of isolated individuals, but is essentially a complex, collective affair of actors with conflicting agendas.

However, if we look a bit closer, there is something peculiar about the way respondents describe the restrictions they feel bounded by. The restrictions of their freedom to act within this network prove not to be a completely fixed matter. Instead, these restrictions seem to be subject to negotiations, and to have a gradual character. This gradual character becomes clear in remarks like: "We only seek collaboration with business organisations on the condition that this results in work that is scientifically relevant". Thus, a rather remarkable inconsistency seems to exist here. On the one hand, engineers refer to the network character of modern technology development to deny moral responsibility for their actions. On the other hand, these same restrictions are not deemed compelling enough to overrule the classic and fundamental demand of scientific relevance. Why then would it not be possible to refuse that same collaboration if other, moral, demands would require this?

This inconsistency, however, can be explained in a sociological way, i.e., by leaving the perspective of the actor and invoking structural factors that shape engineering practice. In that perspective, it is easy to see that respondents are part of two networks: they are part of a network in which business organisations play a major role. But they are also, and probably more fundamentally, part of an academic network. In this latter network, their failure or success is rated according to their scientific prestige, and hardly at all in terms of the possible ethical content of their work - all the more so if that content is not manifest at first sight.

re $C$ Concerning the question to what degree, if at all, the future consequences of new technologies can be predicted, we have seen how respondents came up with five fundamental reasons why this is not the case or, at best, is only the case to a very limited degree. Some of these reasons, however, are more convincing than others. For example, the last argument - that any evaluation of these consequences will be subjective and contested - may be nothing more than an old positivistic reflex: we can agree on hard facts, but not on soft values. Be that as it may, this argument does not really contest that the consequences themselves can in principle be foreseen, only that their desirability may be a matter of subjective taste or political debate. The same holds 
for the argument that good and bad are sometimes inextricably entwined. This is undoubtedly true, but it does not follow that these intricacies cannot or should not be made visible in advance. So this leaves us with the other three reasons why, according to the respondents, it is often impossible to predict the probable consequences of new technologies: they are too complicated, are too long-term, and are independent of the intentions of the designer and are dependent on the future user.

Although we accept that there is considerable truth in these objections, we do wish to point out a rather striking discrepancy between the respondents' modesty when it comes to predicting risks on the one hand, and their willingness to accept credit for success on the other. One plausible way of interpreting this inconsistency is by pointing to the self-interest of our respondents. They seem to manoeuvre for maximum autonomy combined with minimum responsibility. They achieve this feat by alternating between the abovementioned restrictions if someone appeals to their moral responsibility, and referring to their academic freedom when negotiating with business.

\section{A brief case study: Designing biodegradable plastics}

In this section, we describe the case of a technical design process that is relevant because of the attention given to moral aspects in the course of the design activities.

At the end of the 1960s, a new research group (Biomedical Materials) was established within the Department of Macromolecular Chemistry at Twente Technical University. The research topic of the new group was the design and development of biodegradable polymer materials for medical use, e.g., ligature threads and capsules for the delivery of drugs in the body. Such materials have to meet conditions of controlled degradation. That is, they must have vanished from the body within a fixed time span and should not leave healthdamaging debris. The latter objective can be realised by taking natural substances such as lactic and amino acids as a starting point for the design of these medical products.

In contrast to the polymer chains applied in medicine, another polymer material started to stir social concern in the 1970s. Specific synthetic substances ("plastics") widely in use for a range of applications, especially as packing material, had become a major pollution problem. Being nonbiodegradable, they popped up everywhere in the environment as persistent waste. Entrepreneurial scientists scented a market for biodegradable plastics. However, the first attempts to develop such plastics from blends of starch (a 
natural polymer) and polypropylene were not very promising. Now and then, the scientists at U т played with the idea of searching for something better by building on their expertise with biomedical materials, since these materials were completely biodegradable. The apparent societal need for biodegradables might help to acquire the funding needed for additional research. What held them back for a long time was the difference in markets. Medical biopolymer products were technically sophisticated, expensive, and were sold in niche markets at high prices. A biodegradable substance appropriate for use in all kind of packages had to be some kind of cheap bulk material intended for a mass market. The biomedical materials were simply too expensive for this kind of application. For that reason, the scientists in Twente did not take action, but kept an eye on developments.

In 1989, the visit to a scientific conference where "biodegradable materials for the environment" were high on the agenda set the ball rolling. The research group decided to undertake a serious research effort into the development of a biodegradable plastic for bulk application. Since a study of this kind of material did not fit into the regular research program, its development had to be funded by external sponsors. Informal contacts that the group maintained with industry indicated that polyethylene-terephthalate (РЕT) was a promising candidate as a "raw" material. PET already contains degradable bonds, but degrades very slowly since it is very hydrophobic. By building an easily hydrolizable substance into the P ET chain, the U T scientists hoped to lower the hydrophobia and to increase the biodegradability of PET. A quick survey of the literature taught the research team that several substances might prove appropriate, and that there were no patents excluding collaboration with a partner in industry. In 1992, two team members visited a large chemical corporation that was known for researching PET. But for a number of reasons, this firm was not interested in supporting the u t team's efforts to make PET biodegradable. Thus, funding had to be sought elsewhere. Six months later, the "Polymer products and waste management program" (PoWAM) offered a new opportunity.

POWA M, established in 1992, was a multidisciplinary program for environmental research funded by the ut itself. Its objective was "to contribute to possible solutions for the urgent environmental problems stemming from the societal use of synthetic polymers". Funding by powam meant that a research team had to undertake a critical assessment of the technological, societal and political implications of the polymers to be developed. This condition stemmed directly from the SESR policy developed by the Board of the University (see above), now implemented through research programs such as powam. The research group within Biomedical Materials successfully ap- 
plied for powa m funding on behalf of a project called "Biodegradable Polymers to Reduce Polymer Waste", which was started in the spring of 1993. The basic idea of this project - modifying PET to turn it into a biodegradable substance - remained unchanged. However, the obligatory societal assessment which was carried out after the first research year yielded an unexpected outcome. The assumption about the environmental need for a biodegradable plastic, on which the project had been built from the beginning, appeared to be largely unfounded. In the policy-oriented literature, biodegradable plastics were juxtaposed with more sustainable alternatives such as recycling or re-use of packages. To be socially viable, biodegradable plastics would at least have to prove their superiority over these alternatives in comparisons based on robust environmental assessments such as life cycle analysis (LCA). In the Dutch National Policy Plans for the Environment (Nationale Milieubeleidsplannen, NMPS), biodegradable plastics were not even mentioned as an option for alleviating waste problems. These outcomes came more or less as a shock to the researchers involved with PET. They had always perceived biodegradable plastics as a technical solution with a promise embraced by society. Now it became gradually clear to them that they had only been cherishing a vague dream of their own. To come true, this dream had to fit credibly into a developing picture of sustainable waste policy and, to realise this fit, the technical design needed a convincing story and the right performance.

Arguments underpinning and articulating the promise of PET were developed in a book about powam (Smits 1996). In an article about the role of polymers in waste management, the PET researchers carved out a niche for their emerging product by recommending its use in applications ending in waste streams that are hard to recycle, such as those produced by households. After biodegradation, the remainder of such waste can be re-used as biomass or, if degraded anaerobically, as methane. If natural substances can be built into biodegradable polymer products, a neutral $\mathrm{CO}_{2}$ balance is within reach. The authors coined the term "biological recyclability" for this kind of opportunity. Further, they sketched a scenario to underpin the economic viability of large-scale use of biodegradable synthetic polymers in society. According to the authors, this viability presupposes a world in which (i) exhaustion of supplies has driven up oil prices sharply, (ii) the price of biodegradable synthetics has fallen considerably due to increase in scale, (iii) the imposition of taxes on waste favours the use of bio-recyclable products, and (iv) the presence of an adequate infrastructure enables the collection and processing of organic waste. The authors admitted that to acquire a precise picture of the contribution to the alleviation of waste problems, their option of biodegradable polymers had to be tested against alternative solutions by carrying out 
LCAS (Stapert et al. 1996). The P OWA book was presented at a U T workshop ("Plastic Waste: A Technical or a Societal Problem?") which was part of a series of SESR workshops.

In a presentation to a U T conference ("The Moral Script in Technical Design") during the following year (1996), an effort was made to connect the PET project more closely with Dutch waste policy. The researchers agreed that, as this policy stipulates, prevention and re-use of waste are the most desirable options. For the remainder of the waste, the concept of biological recycling had now been further articulated by comparing it with chemical and mechanical recycling. The latter approaches both presuppose separation and collection of different types of waste before recycling can occur. But biodegradable polymers, so the researchers stressed, need no separation from the rest of the organic waste - such as that produced by households - before it can be processed into compost. Another aspect of the societal embedding of biodegradable plastics was their manufacturability. According to the PET engineers, the development of synthetic biodegradables should form the beginning of a technological trajectory which may shift to the more favourable natural (i.e., renewable) polymers in later stages. They perceived commencement with natural polymers as impossible, because processing these substances is too remote from current expertise and practice in the chemical industry.

An explicit design constraint resulting from the societal assessment of the project was "compostability", i.e., the biodegradable plastics must be degradable into compost. Biodegradable plastics can be conceived as artifacts with competing action programs. On the one hand, these plastics must be sturdy for use as bags, covers, etc., whereas, on the other hand, they should quickly weaken and disintegrate when discarded. The composting process can link both programs by offering an accelerated breakdown of materials robust enough for practical use as plastics. Moreover, compostability was required to embed plastics in emerging regimes of processing organic household waste in Dutch cities. These regimes produced compost as an end product. Both considerations meant that the compostability of the biodegradable plastics under development had to be tested. This demand required an extension of the design process by the development of a definition of compostability and the development of a standardised test methodology. These requirements were realised by means of collaboration with a research institute at Wageningen Agricultural University. In 1995, the partners concluded a contract by which Wageningen University committed itself to carrying out biodegradability tests in exchange for support of the Ph.D. fellow in charge by the head of the Biomedical Materials research group at the University of Twente. 


\section{Evaluation of the case study}

As with the interview data, we evaluated the case study against the chosen preconditions for the attribution of ethical behaviour.

\section{A. Actorship and causality}

What kind of actions did the engineers carry out within the practice of the project studied? These actions can be described in different ways. To begin with, our chemical engineers attempted to synthesize new substances called "biodegradable plastics". As we showed, such substances have two contradictory action programs, like safety belts and airbags in cars (Latour 1992). Creating this kind of dual substance is a complicated task requiring sophisticated knowledge, experience, skills, tools and resources, a kind of heterogeneous and connecting activity we call pure science.

At the same time, we can describe the actions of our engineers as entrepreneurial. What they do is attempt to make the knowledge and expertise of their department - biopolymers for medical use - work in the new domain of environmental technology. That is, they want to conquer new territory with new ideas and new products and, in doing so, add value to the investments they have already made.

Furthermore, our engineers hope to build a better society by means of their professional activity. In this sense, there is also a moral incentive behind their activities. By advertising their project, they seem to indicate some kind of responsibility for the unwanted effects of previous endeavours by chemical engineers, that is, the construction of non-degradable plastics, which have become an environmental nuisance. At this point, we should realise that it is quite possible, even probable, that this responsibility for the waste problem is more easily assumed if the development of a technical solution to that problem can be turned into a promising new project from which benefits can accrue. In this sense, some of the opportunism we noticed earlier in the interviews may become manifest here too.

Having discussed the actions, we turn to the causality. In the interviews, the engineers expressed ambivalence on this point. They considered it rather unpredictable which use "society" might make of research outcomes, but not completely unpredictable. In an earlier section, we speculated that this ambiguity has to do with the networks in which the engineers participate in order to realise their designs; that is, to figure them out, to articulate and develop them, and to make them work. Thus, the engineers construct causality themselves, but they are not the only constructors. Their actions are shaped and 
framed by, and attuned to, those of other actors with whom they share networks of collaboration. Indeed, the making of modern technology is a very specialised, multi-actor undertaking (Rip et al. 1995; Rip and Kemp 1998). The current idea among sociologists of technology is that different collectives of actors participating in the development of a specific piece or field of technology are linked up by an "innovation chain" or rather - to borrow a more dynamic and iterative concept - by "techno-economic networks" (Callon et al. 1992). Such networks link activities in science, industry and the market. It is a major goal of modern technology policy to construct such networks, or to close the gaps in them. Causality develops gradually in such networks, while none of the actors is in full control of this development (Elzen et al. 1996).

When we look at the practice as revealed by the case study, it becomes clear how the actions of the engineers acquire a sense of direction. The network(s) in which they operate function(s) as incentive structures shaping their actions and giving them significance in both a cognitive and a social sense. Within the science pole of the network in which our engineers work, the ruling paradigm inspires the course of action in making the new artifacts, i.e., the chemical substances called "biodegradable plastics". The main direction is clear - combine aliphatic hydrophilic carbohydrates with hydrophobic aromatic ones in a polyester molecule to realise the dual "action program" of the molecule. The precise composition of the chain has to be discovered: which groups should be linked, what length the chain should have. That is what most of the experimentation, i.e., the engineering action, is about. To determine these details, the engineers derive ideas from their own experience, from their colleagues within the research team and those they meet at conferences, and from the scientific literature. In other words, they tap the science (part of the) network. But they know that to make their molecules work in society, these have to be processed into products on a mass scale. It is quite clear that they lack the resources and skills to do that themselves. In fact, they have no equipment to test their molecules for this purpose. Therefore, actors in industry are needed - another (part of the) network. To interest these actors and to link them to their project, the molecules in question have to meet certain requirements. Our engineers assume that they have to offer a substance that is easy and cheap to produce on a large scale, a bulk product, otherwise their molecule will have no chance. This also requires research effort because the biomedical polymers with which they are familiar are expensive and can only be sold in niche markets (hospitals). Further beyond, that is, beyond industry and its supposed demands, there lies a "society" in which the biodegradable molecules might eventually be used. Our engineers have the idea that their molecules hold a promise for solving, or at least mitigating, the 
waste problem that "society" is wrestling with, but this idea is only a very vague one. It is based on a very general and unchecked scenario announcing that waste problems due to plastics will aggravate to the extent that "society" will embrace any biodegradable plastic as soon as it can be produced.

Thus, there is a sense of causality in making biodegradable plastic right from the beginning. This is inevitable, of course, otherwise there would be no project. However, the more the distance from the science pole - the workplace of our engineers - increases, the more the articulation of this causality declines. Our engineers are quite capable of explaining in detail those molecules that will probably work in "technical" terms. However, with regard to the question as to how such molecules will be adopted into society and how they will work in "social" terms, the engineers only have vague answers. In the interviews, there was some speculation about the reason for such difference in articulation, in the sense that the structure at the science pole lacks incentives to elaborate the "social side". Indeed, the case study makes clear that the primary concerns of the engineers are the originality of their findings and the possibility of protecting them by a patent. In the next sections, we shall see that as soon as the incentive structure becomes more rewarding in this respect, investments will be made to also cover the "social" part of the venture, with stunning outcomes.

\section{B. Freedom of design and the societal effects of research}

In the interviews, the engineers emphasised that the financial need to collaborate with industry constitutes a severe limitation of their academic freedom: "the need for money leaves little room for principles". This quote suggests that industry more or less dictates the kind of research that academic research teams should perform. Our case study did not confirm this situation. It is rather the other way around, in the sense that our researchers tried (in vain) to enroll firms in an academic project. The mainsprings of this initiative were entrepreneurial incentives mixed with some principles, and encouragement from the outcome of a feasibility study allied to some initial interest from the side of industry. The case study alone does not prove, of course, that this kind of development pattern is a general one, but it does suggest that the statements on this point in the interviews are questionable. ${ }^{6}$

The second aspect of freedom we distinguished is the freedom to investigate the societal effects of the research being carried out; that is, to undertake efforts directed at impact assessment. In the interviews, the engineers provided strong opinions about this point: the research context does not welcome, let alone reward, the assumption of a moral stance on a project. Consequent- 
ly, there is a lack of incentives and resources for activities aiming at impact assessment. This situation is taken as the reason why engineers "work hard on the technical side [of a research project], but not on the social side".

Such opinions can primarily be explained from the engineers' entrepreneurial role. The case study shows that, to keep the project alive, the engineers have to sell it to sponsors. In this pursuit of resources, the natural tendency is to emphasise the promise of biodegradable polymers. Falsifying this promise, i.e., inquiring into the "negative social consequences" of these polymers, would be counterproductive. In addition, the engineers' distinction in the project between the "technical" and "social" aspects of their work on biodegradables is remarkable. This kind of duality in their discourse seems to indicate that they may not be aware of the fact that their technical activities shape a social reality through a developing causality as sketched above. That is, they help to create a society in which biodegradability makes the use and the jettisoning of plastics on a massive scale even more attractive. Another possibility is that polymer engineers are more or less aware of this, but their opinions refer to a difference in degree of articulation regarding the various kinds of research activities, as we explained earlier. That is, research on matters of societal impact (how the desirability of biodegradable plastics precisely relates to existing priorities in waste policy, etc.) suffers from a lack of attention and resources, compared with molecular research itself, and therefore these matters remain vague. The concern about such societal questions is delegated to industry, which is "closer to the practical problems". Our engineers seem to have a division of labour in mind: we deliver a cheap bulk polymer, they dream up the applications for they know the market! This is indeed a division of labour leaving our engineers a maximum of room to manoeuvre.

The establishment of the university-sponsored Powam program changed this incentive structure significantly. In the framework of this program, the polymer engineers were seriously engaged in impact assessment, since the program required this as one of the conditions of receiving funds. Now they have to elaborate their vague scenario of future developments in societal waste management. In the effort to articulate their ideas, they discovered that the world outside academia is different from what they thought.

\section{Knowledge about the societal effects}

Again referring to the interviews, we recall that the engineers interviewed mentioned five reasons that more or less made the exploration of the consequences of their design work impossible. On the basis of these data, we might expect the engineers to protest against the impossible task placed on their 
shoulders by the PoWAM program requirement to assess the societal consequences of their technical project on degradable polymers. Strangely enough, they do not protest. Within the practice of the PoWA project, the engineers dug into the future quite zealously instead of sitting back and complaining about the complexities of the "social" world. On the one hand, they forecasted a world in which their biodegradable polymer would find a niche and would have opportunities. In this scenario, the engineers do not shrink back from predicting the development of different kinds of socio-economic factors in the long term, from oil supplies to green taxes. They also mapped out a technological route within which the development of biodegradable plastics could be imagined to take place, and they emphasised the advantages of biological recycling (i.e., not requiring separation of waste) compared with the alternatives of the moment, i.e., chemical and mechanical recycling, that rank higher in political terms. The consequence of this scenario is that biodegradable plastics should be compostable, that is, the design requirements changed. As a consequence, the network around the project had to expand to include partners (found at Wageningen University) able to realise this societal inscription in the molecule.

In other words, our engineers do not try to predict the manifold and longterm consequences of their technology, i.e., of the molecules they had constructed. This would indeed be an impossible task. Instead, they develop an educated forecast of the social world that the technical concept of biodegradable plastic is expected to meet, and they adapt the molecular design accordingly. Thus they do not sit passively, simply leaving the fate of their molecules to unpredictable "users" in society. Which means that our engineers are not only acting as technical engineers "only constructing molecules", but they are also acting as social engineers.

\section{Discussion and conclusions}

In the interviews we have analysed, scientists refer to constraining structural factors as a primary cause for the lack of agency they experience in matters of social responsibility related to their research. That is, our scientists do not consider themselves as autonomous seekers of truth. In morally accounting for their actions as researchers, they rather take their environment as a reference. The way in which they describe the restrictions they experience in behaving responsibly comes close to the picture that modern sociology of science draws of the modern scientist, namely, as an actor whose agency is enabled and constrained by structure, i.e., by the technical frames (Bijker 1995 ${ }^{\mathrm{a}}$ ) 
and the networks s/he needs for the "co-production" (Rip et al.1995), "realisation" (Radder 1996) or "construction" of techno-scientific (arti)facts (Latour and Woolgar 1979). In the relationships referred to by the scientists interviewed, commercial sponsors appear as the dominant actors to be taken into account, with users being regarded as determining the final effects of technical designs. It is remarkable that the interviewees apparently perceive these actors, especially the users, as being much more autonomous in their actions - that is, less constrained by structure - than they themselves in their role as scientists. Consequently, they attribute to these actors more responsibility for the impact of technology than they are willing to take themselves.

Though it is clear that research is to be carried out in an "impure" world where the scientist has to keep the low company of commercial interests, our interviewees stick to formulating their mission as "pure research". A kind of purification seems to be going on here enabling the immaculate scientist to make the vulgar allies responsible as soon as the outcomes of joint efforts become a social problem. As to becoming knowledgeable about the societal effects of their professional activities, the engineers feel equally constrained. The character of the restrictions they mention corresponds closely with the outcomes of analyses made in the field of technology studies, such as the recognition of a control dilemma inherent in the assessment of social effects of technology (see e.g., Collingridge 1980). Moreover, as far as these effects can be assessed at an early stage, the interviewees perceive no incentives spurring them to do so within their professional academic environment. The engineers interviewed meet the issue of their social responsibility with a mixture of fatalism and opportunism. Their argument on which this attitude rests can be summarised as follows: in our professional environment, the structural conditions to behave responsibly are not fulfilled, so we cannot be moral actors. Where things go wrong, we cannot be held accountable.

We appreciate the engineers' account as an adequate assessment of the moral position of today's individual scientist. It leads us to the conclusion that the three basic preconditions for the attribution of moral responsibility do not apply in the situation of the present-day individual scientist. To force such responsibility on these scientists individually would indeed lead to moralism. However, by accepting this conclusion, the engineers would escape too easily. When we look through the lens of the case study at the actual behaviour of the scientists, they do not appear quite so helpless. In developing biodegradable polymers, the engineers do not seem to play their modern role as entrepreneurial co-producers of technology in a reluctant manner. On the contrary, they tend to play it actively and emphatically. Indeed, this means that they are not individual truth seekers but dedicated team workers and 
network builders. This is the very role that society expects nowadays from, and attributes to, the workers at the science pole of the modern "knowledge infrastructure". In fact, playing the entrepreneurial role well could be conceived as a major characteristic of the societal responsibility of the modern scientist. ${ }^{7}$ Knowledge workers at the science pole are supposed to come up with a constant stream of new ideas and to make these ideas work by inscribing them into hardware (in our case, into specific molecules), by attracting funds, and by building new alliances. However, in order to create any room to manoeuvre and to raise funds, the inscriptions to be made should have at least some credibility of future pay-off for both the scientists themselves and for other investors. For that reason, a narrative is developed that includes promises about and forecasts of future effects - such as "reducing the waste problem" - to be realised by the new (but still fictive) molecules. Such promises and forecasts build a "prospective structure" guiding further action and resource building (Van Lente and Rip 1998). Thus, despite the fact that anticipations of societal effects are qualified as inherently difficult if not impossible in the interviews, the scientists do speak out about such effects as a precondition for creating this kind of prospective structure. However, the social effects suggested as issuing from the new research path of biodegradable plastics are very imprecise. Moreover, these promises are constructed in a narrow setting (the science pole), and their reliability is not checked against the wisdom of external experts by broadening the network towards relevant policy circles. In other words, politics within science (the technical inscriptions made in conjunction with the local narrative justifying these inscriptions) is disconnected from the wider societal politics. We suppose that this is the normal way of shaping social responsibility as it occurs in modern scientific practice, but it is a rather narrow-minded and not very productive one. For as long as the moral promises and forecasts about desirable social effects of research conceived at the science pole are not embedded in the views and actions of other actors crucial for "realisation" or "co-production" - i.e., as long as they are kept "pure" - they will never fulfil their sweet-sounding prophecies.

Appraising the tension between what our chemical engineers say and what they do, we might conclude that they are trapped in the duality of structure (Giddens 1984). The very structures they build and reify as a frame for their entrepreneurial agency are experienced by these same scientists as given constraints shackling their social responsibility. Because of this hidden duality, the science pole seems to (dis)function as a morally unreflective, reproductive Boudonian system lacking feedback from its environment. Such systems can begin to learn and to transform when they start to generate a certain level of aggression in their environment (Boudon 1974). 
The establishment of a collaborative agreement between the research group of the Technical Physics Department and Urenco (see section 2) did trigger such aggression. The Department, and the Board of the University in its wake, came under moral pressure to re-assess research goals because of the possibly unwanted societal effects (military applications of laser enrichment of uranium). The change of institutional rules for internal funding of research projects resulting from this clash created an incentive structure more favourable to moral agency at the research team level. The addition of a societal assessment clause to project funding conditions had a profound influence on the further development of the polymer project at the network building level as well as with regard to the technical content of the project. After a serious exploration of Dutch waste policy in relation to the idea of making plastics biodegradable, the rationale of the project became much more articulated and changed considerably, as appears from the article in the book about PowA M. Accordingly, the project was steered away from mere biodegradability towards compostability of plastics, an aim which fitted much better into current waste policy. In turn, this socio-technical change required changes in network building around the project. The research team no longer aimed at establishing relations with large firms to develop a bulk product, but became interested in small firms exploring niche markets for compostable plastic products like waste bags instead. To test the compostability of the prototypes of the molecules designed, the team initiated collaboration with a research group at another university. In other words, due to the change in rules, the science pole started to be more sensitive to its environment, became morally reflexive about its research aims and about the resulting molecular inscriptions, and recruited different allies. Moreover, it articulated a much more realistic scenario about the future world in which its research product would function i.e., more in agreement with the agendas of crucial partners for further development - than before. Finally, politics within science became connected and attuned to wider societal politics.

Though the perceptions and concerns of practitioners with regard to the bounds of modern technoscience enterprise should be taken seriously, they do not force us to conclude that we should dismiss the notion of the engineer's individual moral responsibility. Rather, a sociologically informed way of studying engineering practice helps to reveal the particular moments and particular characteristics of practice at which and by which the conditions to execute this individual responsibility are favourable or limiting. We have tentatively demonstrated this by examining the normal practice of engineers in an analysis of their perceptions as made clear in interviews, and in an investigation of their real actions in a case study. The outcome of this analysis is that 
engineers simultaneously strategically operate within and refer to the structural (i.e., network-like) character of their practice as a ground for shifting moral responsibility to others. Our own conclusion is different; namely, that recognition of this structural character opens new options for agency regarding the responsibility of engineers.

At the same time, we do not deny that, for individual engineers, it is difficult to realise these options on their own. The P owam experience shows that to create incentives for engineers to assume social responsibility, the individual engineer level has to be transcended, and initiatives for policy making have to be taken at the institutional and societal level. Thus, reflection and research on how engineers can contribute to the shaping of institutions, procedures and instruments that allow the social assessment of specific design activities, and the democratic deliberation upon these, should be part and parcel of engineering ethics. On the institutional level at the science pole (the part of techno-economic networks that is the focus of our analysis), one could imagine initiatives to be taken such as:

- creating funds at the university or faculty level for the assessment of projects expected to have considerable and/or ambivalent societal impact

- developing best practice methodologies for supporting engineering scientists in carrying out such assessments at the research team level (Jelsma and Van de Poel 1992)

- evaluating experiences with assessment practice at the faculty level from time to time

- striving for diversity and richness of networks around design projects. ${ }^{8}$

Further suggestions can be found in the literature about constructive and interactive forms of technology assessment (Rip et al. 1995). For research teams in industry, suggestions for impact analysis and tools for network management and social learning have been described by Deuten et al. (1997). Project managers directing radical innovations can turn to the Socrobust approach for help in revealing the kinds of social environment presupposed by such innovations (Larédo et al. 2002). Further steps taken to enhance the social accountability of firms could provide leverage at the research team level at the science pole, too, but discussing such mechanisms is beyond the scope of this study. With respect to any such assessment initiatives taken, it is important to stress that they should not be restricted to the societal impact of technical design projects but should also include the contingent framing of the design activity within networks and their related issues such as access, openness, diversity, ownership, etc. 
The foregoing considerations lead us to the following conclusions. First, structural conditions for taking individual moral responsibility in the normal practice of engineering at the science pole can be developed and realised, but engineering ethicists pay little attention to this course of action because of their pre-occupation with exceptional cases, i.e., cases of whistle blowing. Second, such structural conditions can only be created by initiatives at higher structural levels, that is, above the work floor of engineering where practising engineers are not the primary actors. However, this does not mean that engineers are powerless in this respect. In our view, they are free to urge such initiatives in a timely manner. That is, our study constructs a second-order responsibility for engineers, one that urges them to strive actively for the creation of conditions on the engineering work-floor that enable the assumption of moral responsibility by individual engineers.

\section{Notes}

1 Compare for example: Martin and Schinziger (1996). This much-used book defines engineering ethics as (1) the study of the moral issues and decisions confronting individuals and organisations involved in engineering; and (2) the study of related questions about moral conduct, character, policies, and relationships of people and corporations involved in technological activity (p. 23; also quoted in Lynch and Kline 2000, 196).

2 See, for example, Duff (1998) or Velasquez (1998). But any other textbook will roughly give the same conditions, albeit phrased differently or with a different emphasis.

3 Compare, for example, Velasquez (1998). A lot of debate centres on the question of whether a person is always responsible if these four conditions are met. For example, if I freely and knowingly cause my competitor to go bankrupt, am I morally responsible for his or her misery? However, there is considerably less disagreement on the opposite question: Can one be held responsible if one or more of these conditions is not met? In everyday reality, we seem to agree that in that case, we do not hold a person responsible for her or his deeds and their consequences. However, more often than not, it is a matter of degree as to how far these ideal conditions are met: you co-caused the action, you foresaw some of the consequences, you had some freedom to perform the actions (or not), etc. This means that responsibility is often not completely annihilated when conditions are not perfectly met, but mitigated. However, the mitigating power of circumstances is itself a matter of relative weight: if the consequences of our acting (or not) are very serious or severe, a simple reference to our lack of foresight will often not do: even if you did not fore- 
see the consequences, this does not lift your responsibility because you should have known.

4 Compare Vaughan (1996) who shows that, in fact, there was no clear opposition between engineers and management. This opposition was construed afterwards to fit the prevailing conceptions of the professional responsibility of engineers.

5 As the rest of our article indicates, our contention is that networks do have agency in the sense that they enable and constrain the moral agency of the individuals they connect, but they have no moral agency. Of course, networks, institutions and organisations can be made responsible - as Shell was made responsible by Greenpeace for its intention to sink the Brentspar - but this is a pragmatic solution to the practical difficulty of pinpointing responsible individuals in complex networklike settings.

6 The suggestion made here can be further supported on the basis of outcomes from an evaluation study in which one of us participated. From this study-on the spending of governmental funds to research groups in the field of agricultural biotechnology - it appeared that most of these research groups had regular contact with a circle of clients from industry who consulted them about new directions and findings in academic research, as an input for the development of new product ideas. "Not only the small firms hunt us for new product ideas. You would be astonished to know how many big firms are milking us dry by inquiring about which new products they should develop," one researcher told the evaluators (Enzing et al.1992).

7 Such expectations about the social role of scientists are revealed by occasional complaints from Dutch politicians about the lack of entrepreneurial spirit among academics. For instance, at the launch of a governmental program to support innovative start-up firms in biotechnology in early 2000 (to the value of $€ 45$ million), the Minister of Economic Affairs blamed the perceived Dutch arrears in biotechnology for this academic laxity.

8 To give an example of at least some diversity, the Energy Research Centre of the Netherlands (ECN) does much contract research work for the innovation- and market-oriented Ministry of Economic Affairs, propagating and implementing "green energy". In 2000, ECN also carried out a study for Greenpeace, to investigate how green "green energy" really is. 